\title{
Effect of angiotensin-(1-7) on reperfusion arrhythmias in isolated rat hearts
}

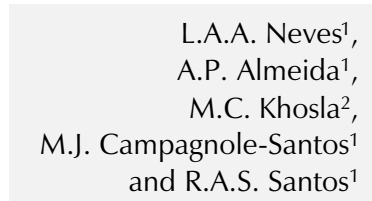

L.A.A. Neves' A.P. Almeida ${ }^{1}$, M.C. Khosla ${ }^{2}$ and R.A.S. Santos ${ }^{1}$

\author{
${ }^{1}$ Laboratório de Hipertensão, Departamento de Fisiologia e Biofísica, \\ Instituto de Ciências Biológicas, Universidade Federal de Minas Gerais, \\ 31270-901 Belo Horizonte, MG, Brasil \\ ${ }^{2}$ Cleveland Clinic Foundation, Cleveland, $\mathrm{OH}$ 44122, USA
}

\begin{abstract}
Correspondence
R.A.S. Santos

Laboratório de Hipertensão

Departamento de Fisiologia

e Biofísica, ICB, UFMG

Av. Antonio Carlos, 6627

31270-901 Belo Horizonte, MG

Brasil

Fax: 55 (031) 441-0835/448-1291

E-mail: marrob@oraculo.lcc.ufmg.br

Research supported by FAPEMIG and CNPq. L.A.A. Neves was the recipient of a CNPq fellowship. $\ldots \ldots \ldots \ldots \ldots \ldots \ldots$
\end{abstract}

Received September 4, 1996 Accepted April 15, 1997

\begin{abstract}
There is increasing evidence that angiotensin-(1-7) (Ang-(1-7)) is an endogenous biologically active component of the renin-angiotensin system (RAS). In the present study, we investigated the effects of Ang(1-7) on reperfusion arrhythmias in isolated rat hearts. Isolated rat hearts were perfused with two different media, i.e., Krebs-Ringer (2.52 $\mathrm{mM} \mathrm{CaCl}_{2}$ ) and low-Ca ${ }^{2+}$ Krebs-Ringer $\left(1.12 \mathrm{mM} \mathrm{CaCl}_{2}\right)$. In hearts perfused with Krebs-Ringer, Ang-(1-7) produced a concentration-dependent (27-210 $\mathrm{nM}$ ) reduction in coronary flow (25\% reduction at highest concentration), while only slight and variable changes in contraction force and heart rate were observed. Under the same conditions, angiotensin II (Ang II; 27 and $70 \mathrm{nM}$ ) produced a significant reduction in coronary flow (39\% and $48 \%$, respectively) associated with a significant increase in force. A decrease in heart rate was also observed. In low-Ca ${ }^{2+}$ Krebs-Ringer solution, perfusion with Ang-(1-7) or Ang II at $27 \mathrm{nM}$ concentration produced similar changes in coronary flow, contraction force and heart rate. In isolated hearts perfused with normal Krebs-Ringer, Ang-(1-7) produced a significant enhancement of reperfusion arrhythmias revealed by an increase in the incidence and duration of ventricular tachycardia and ventricular fibrillation (more than 30-min duration). The facilitation of reperfusion arrhythmias by Ang-(1-7) was associated with an increase in the magnitude of the decreased force usually observed during the postischemic period. The effects of Ang-(1-7) were abolished in isolated rat hearts perfused with low-Ca ${ }^{2+}$ Krebs-Ringer. The effect of Ang II $(27 \mathrm{nM})$ was similar but less pronounced than that of Ang-(1-7) at the same concentration. These results indicate that the heart is a site of action for Ang-(1-7) and suggest that this heptapeptide may be involved in the mediation of the cardiac effects of the RAS.
\end{abstract}

\section{Introduction}

A large body of data has been accumulated regarding the existence of a local, independently regulated, myocardial renin-angiotensin system (RAS) $(1,2)$. Besides the direct modulation of cardiac function through

\section{Key words}

- Renin-angiotensin system

- Reperfusion arrhythmias

- Angiotensin-(1-7)

- Coronary flow

- Isolated heart effects on coronary vascular tone, myocardial contractility, neurotransmitter release from sympathetic nerve endings and cardiac growth, the cardiac RAS appears to be involved in post-ischemic reperfusion arrhythmias (3).

Until recently the systemic or local ef- 
fects of the RAS were attributed solely to the interaction of the octapeptide angiotensin II (Ang II) with its receptors (1). Over the past few years, however, other endogenous biologically active products of the RAS have been identified including angiotensin-(1-7) (Ang-(1-7)) (4,5) and angiotensin-(3-8) (Ang(3-8)) (6). Among the biologically active end-products of the RAS, the heptapeptide Ang-(1-7) is particularly interesting because it can be formed directly from angiotensin I by an angiotensin converting enzyme (ACE) independent pathway (7-9) and is essentially devoid of effects exerted by Ang II through $\mathrm{AT}_{1}$ receptors including vasoconstriction and induction of drinking $(4,10)$.

ACE inhibitors have beneficial effects on reperfusion arrhythmias which have been attributed to a reduction of both local Ang II generation and bradykinin degradation (3). However, plasma Ang-(1-7) concentration increases several-fold during treatment with ACE inhibitors $(11,12)$. Furthermore, Ang(1-7) has been recently reported to produce vasodilation in canine coronary artery rings pre-constricted with the thromboxane $\mathrm{A}_{2}$ analogue U46619 (13) and to increase the release of $\left[{ }^{3} \mathrm{H}\right]$ norepinephrine from isolated rat atria (14). These observations suggest that Ang-(1-7) can participate in the pharmacological effects of ACE inhibitors in the reperfusion arrhythmias. However, there are no data regarding the effects of Ang-(1-7) on ischemic hearts. In this study we evaluated the role of Ang-(1-7) in post-ischemic reperfusion arrhythmias by determining its effects on isolated rat hearts.

\section{Material and Methods}

Male Wistar rats (200-300 g body weight) were decapitated $15 \mathrm{~min}$ after intraperitoneal injection of $200 \mathrm{IU}$ heparin. The thorax was opened and the heart was carefully dissected and perfused with Krebs-Ringer solution or a low-Ca ${ }^{2+}$ Krebs-Ringer solution through a $1.0 \pm 0.3 \mathrm{~cm}$ aortic stump. The perfusion fluid was maintained at $37 \pm 0.1^{\circ} \mathrm{C}$, with a pressure of $65 \mathrm{mmHg}$ and constant oxygenation $\left(5 \% \mathrm{CO}_{2}\right.$ and $\left.95 \% \mathrm{O}_{2}\right)$. A force transducer (model BG-25 g, Gould, Valley View, $\mathrm{OH}$ ) was attached through a heart clip to the apex of the ventricles to record the contractile force (developed tension) on a Gould recorder (model RS 3200). A diastolic tension of $1.0 \mathrm{~g}$ was applied to the heart. Electrical activity was recorded with an electrocardiograph (Nihon Kohden, Tokyo, Japan) with the aid of two cotton wicks placed directly on the surface of the right atrium and left ventricle (bipolar lead). Coronary flow was measured by collecting the perfusate over a period of $30 \mathrm{~s}$ at regular intervals. The composition of the perfusion solutions was as follows: 1) Krebs-Ringer solution: $118.6 \mathrm{mM} \mathrm{NaCl}, 4.75 \mathrm{mM} \mathrm{KCl}$, $2.52 \mathrm{mM} \mathrm{CaCl} 2,2.52 \mathrm{mM} \mathrm{KH} \mathrm{PO}_{4}, 1.17$ $\mathrm{mM} \mathrm{MgSO} 4.7 \mathrm{H}_{2} \mathrm{O}, 25.0 \mathrm{mM} \mathrm{NaHCO}$ and $11.0 \mathrm{mM}$ glucose, and 2) low- $\mathrm{Ca}^{2+}$ KrebsRinger solution: $118.6 \mathrm{mM} \mathrm{NaCl}, 4.75 \mathrm{mM}$ $\mathrm{KCl}, 1.12 \mathrm{mM} \mathrm{CaCl}, 2.52 \mathrm{mM} \mathrm{KH} \mathrm{PO}_{4}$, $1.17 \mathrm{mM} \mathrm{MgSO}_{4} .7 \mathrm{H}_{2} \mathrm{O}, 25.0 \mathrm{mM} \mathrm{NaHCO}_{3}$ and $11.0 \mathrm{mM}$ glucose.

The hearts were allowed to equilibrate for 20-30 min and then perfused for an additional 20 min with Krebs-Ringer solution (control group) or Krebs-Ringer solution containing Ang-(1-7) (27, 70 or $210 \mathrm{nM}$ ) or Ang II (27 or $70 \mathrm{nM})$. Each isolated heart was perfused with only one concentration of peptide ( $\mathrm{N}=3-11$ for each concentration). To study the effect of Ang-(1-7) and Ang II on the reperfusion arrhythmias isolated hearts were perfused for an initial 20-min period with 1) Krebs-Ringer solution (control, $\mathrm{N}=$ 11), 2) Krebs-Ringer solution containing Ang-(1-7) (27 nM, N = 8) and 3) KrebsRinger solution containing Ang II ( $27 \mathrm{nM}, \mathrm{N}$ =6). Since the biological effects of Ang-(17) are considered to be independent of calcium, additional hearts were perfused with 4) low- $\mathrm{Ca}^{2+}$ Krebs-Ringer solution ( $\left.\mathrm{N}=5\right)$, 5) low-Ca ${ }^{2+}$ Krebs-Ringer solution containing Ang-(1-7) (27 $\mathrm{nM}, \mathrm{N}=4)$, and 6) low- 
$\mathrm{Ca}^{2+}$ Krebs-Ringer solution containing Ang II ( $27 \mathrm{nM}, \mathrm{N}=2)$. Immediately after the 20 min perfusion period, the left anterior descending coronary artery was ligated by the method described by Lubbe et al. (15) beneath the left auricular appendage together with the adjacent veins. The ligature was released after 15 min and reperfusion with different Krebs-Ringer solutions (above) was performed for an additional $30 \mathrm{~min}$. Cardiac arrhythmias were defined as the presence of ventricular tachycardia and/or ventricular fibrillation after the ligature of the coronary artery was released. In order to obtain a quantitative measurement, the arrhythmias were graded arbitrarily according to their duration considering a duration of $30 \mathrm{~min}$ as irreversible arrhythmia. Therefore, the occurrence of cardiac arrhythmias for up to 5 min was assigned the factor $1,10 \mathrm{~min}$ was assigned the factor 2, $15 \mathrm{~min}$ was assigned the factor 3, 20 min was assigned the factor 6, 25 min was assigned the factor 9 , and 30 min was assigned the factor 12 . A value of 0-12 was thus obtained in each experiment and is denoted "arrhythmia severity index" (ASI) $(16,17)$. Data are reported as means \pm SEM. Statistical analysis was performed by the Student $t$-test or ANOVA followed by the Least Significant Difference test or the Newman-Keuls test, when appropriate. The level of significance was set at $\mathrm{P}<0.05$.

\section{Results}

The averaged basal values for contraction force, heart rate and coronary flow in isolated rat hearts $(\mathrm{N}=58)$ perfused with normal Krebs-Ringer solution were $8.35 \pm$ $0.21 \mathrm{~g}, 264 \pm 7 \mathrm{bpm}$ and $7.92 \pm 0.35 \mathrm{ml} / \mathrm{min}$, respectively. When the isolated rat hearts $(\mathrm{N}$ = 11) were perfused with low-Ca ${ }^{2+}$ KrebsRinger there was, as expected, a decrease in contraction force to $6.61 \pm 0.39 \mathrm{~g}$ that was not accompanied by changes in heart rate $(260 \pm 9 \mathrm{bpm})$ or coronary flow $(7.80 \pm 0.68$ $\mathrm{ml} / \mathrm{min}$ ).
Figure 1 shows the percentage of change in contraction force, heart rate and coronary flow in isolated hearts perfused with normal Krebs-Ringer solution or normal KrebsRinger solution containing different concentrations of Ang-(1-7) and Ang II. No significant differences were observed in contraction force $(7.60 \pm 0.47 \mathrm{~g} v s 7.76 \pm 0.73 \mathrm{~g}$ at the end of the equilibration period), heart rate $(278 \pm 14 \mathrm{bpm} v s 260 \pm 21 \mathrm{bpm}$ at the end of the equilibration period), or coronary flow $(9.03 \pm 1.10 \mathrm{ml} / \mathrm{min} v s 9.12 \pm 1.04 \mathrm{ml} /$ $\mathrm{min}$ at the end of the equilibration period) in isolated hearts perfused with normal KrebsRinger solution. Perfusion of isolated hearts with normal Krebs-Ringer solution containing Ang-(1-7) did not consistently change
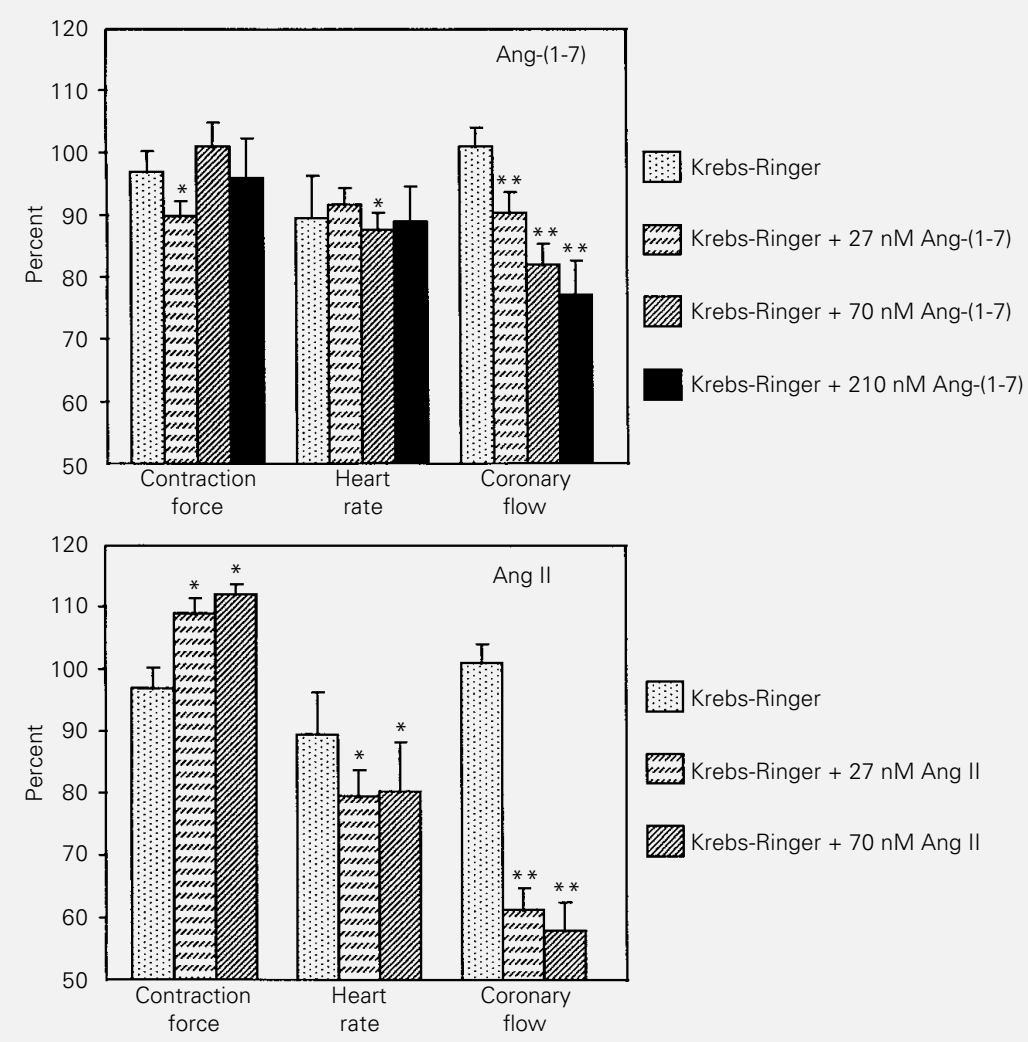

Figure 1 - Contraction force, heart rate and coronary flow in isolated rat hearts perfused with 1) Krebs-Ringer solution (control, $N=9$ ); 2) Krebs-Ringer solution containing Ang-(1-7) concentrations of $27 \mathrm{nM}(\mathrm{N}=9), 70 \mathrm{nM}(\mathrm{N}=9)$, or $210 \mathrm{nM}(\mathrm{N}=3)$ and 3) Krebs-Ringer solution containing Ang II concentrations of $27 \mathrm{nM}(\mathrm{N}=11)$, or $70 \mathrm{nM}(\mathrm{N}=6)$. ${ }^{*} \mathrm{P}<0.05$ compared to the end of the equilibration period (Student $t$-test for paired observations) ${ }^{*} \mathrm{P}<0.05$ compared to the end of the equilibration period and the control group (Student $t$ test for paired observations and ANOVA followed by the Newman-Keuls test). 
Figure 2 - Coronary flow (upper), contraction force (middle) and diastolic tension (lower) in isolated rat hearts perfused with KrebsRinger solution (control, $\mathrm{N}=11$ ), Krebs-Ringer solution containing 27 nM Ang-(1-7) ( $\mathrm{N}=8$ ) or KrebsRinger solution containing 27 nM Ang $\|(N=6)$ before and after (reperfusion) coronary occlusion. Percentage was calculated in relation to the last value of the equilibration period. ${ }^{*} P$ $<0.05$ compared to the control group (ANOVA followed by the Least Significant Difference test). contraction force or heart rate. However, a concentration-dependent decrease in coronary flow of $10 \%, 18 \%$ and $25 \%$ was observed with Ang-(1-7) concentrations of 27 $\mathrm{nM}(\mathrm{N}=9), 70 \mathrm{nM}(\mathrm{N}=9)$ and $210 \mathrm{nM}(\mathrm{N}=$ 3 ), respectively (Figure 1).
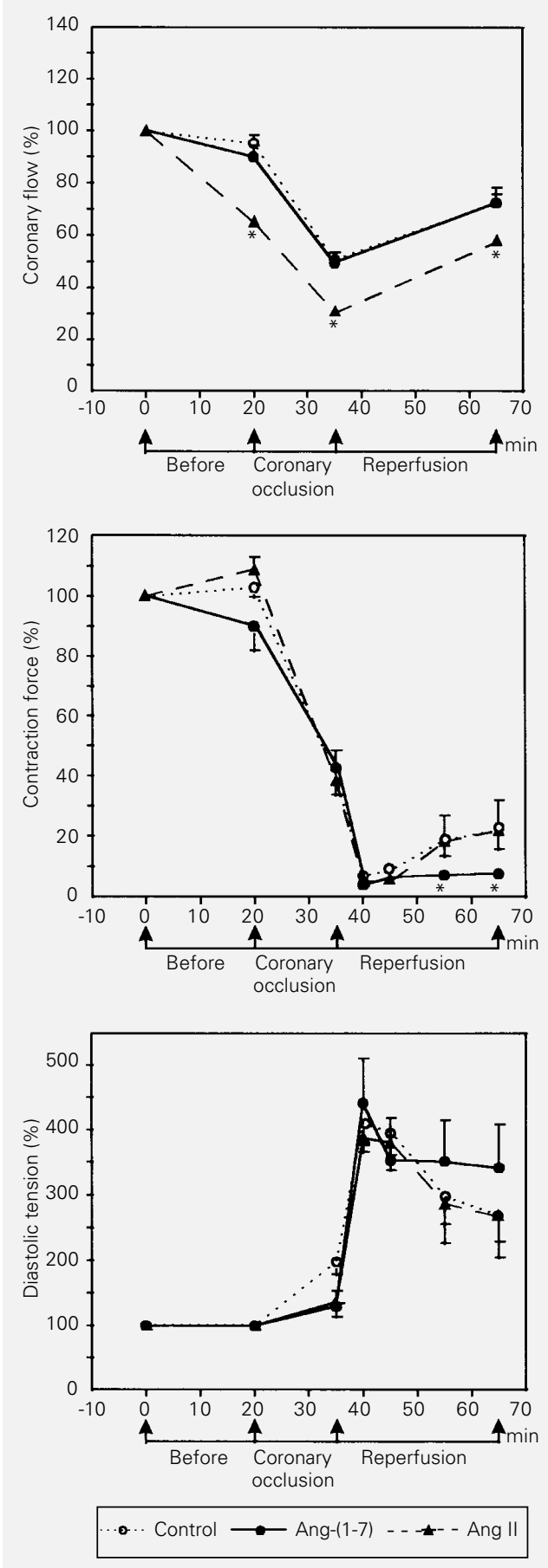

In contrast, Ang II produced a dose-dependent increase in contraction force $(9 \%$ and $12 \%$ at $27 \mathrm{nM}$ and $70 \mathrm{nM}$ concentrations, respectively, Figure 1) and a decrease in heart rate (approximately $20 \%$ at both concentrations, Figure 1). In addition, Ang II markedly reduced the coronary flow by $39 \%$ and $48 \%$ at concentrations of $27 \mathrm{nM}$ and 70 $\mathrm{nM}$, respectively (Figure 1). Under basal conditions no changes in diastolic tension were produced by Ang-(1-7) or Ang II.

Occlusion of the coronary artery in other rat hearts resulted in a comparable flow reduction (approximately 50\%), which was sustained throughout the ischemic period. The flow reduction was associated with a marked decrease in contractility $(60 \%)$ without major changes in diastolic tension. The changes in coronary flow in the hearts perfused with Ang II were greater than those of the control group since a significant decrease $(35 \%)$ in flow was already observed before occlusion. A slight decrease in heart rate was also observed during ischemia in all groups (data not shown). Figures 2 and 3 graphically show the percentage of change in coronary flow (before, after 15 min of coronary occlusion and after $30 \mathrm{~min}$ of reperfusion) and the percentage of change in contraction force and diastolic tension (before, after 15 min of coronary occlusion and after 5, 10, 20 and $30 \mathrm{~min}$ of reperfusion).

Upon reperfusion, coronary flow increased to values corresponding to approximately $80 \%$ of the values before occlusion. However, upon reperfusion there was an initial further decrease $(35 \%)$ in contraction force and a significant increase $(250 \%)$ in diastolic tension in all groups (Figure 2). In addition, following the initial increase in diastolic tension a small decrease was observed for all groups (Figure 2). The initial decrease in force was followed by a small gradual increase in the control and Ang IIperfused hearts (Figure 2). In contrast, in the hearts perfused with Ang-(1-7) no apparent recovery was observed (Figure 2 ). 
When the isolated hearts were perfused with low-Ca ${ }^{2+}$ Krebs-Ringer solution, addition of Ang-(1-7) or Ang II produced results in basal heart rate (data not shown) and contraction force and coronary flow (Figure 3) similar to those observed with normal KrebsRinger. Coronary occlusion in low $\mathrm{Ca}^{2+}$ perfused hearts also produced a significant decrease in coronary flow associated with a decrease in contraction force without changes in diastolic tension (Figure 3). Upon reperfusion, the initial changes were also similar to those of normal Krebs-Ringer-perfused hearts except for the changes in diastolic tension that were more modest (Figures 2 and 3). However, different from the data observed with normal Krebs-Ringer, after these initial changes there was an increase in contraction force accompanied by a complete recovery of diastolic tension for control, Ang IIand Ang-(1-7)-perfused hearts (Figure 3).

Ventricular tachycardia and/or ventricular fibrillation upon reperfusion were observed in all groups. A facilitatory effect of Ang-(1-7) on reperfusion arrhythmias in isolated hearts perfused with normal KrebsRinger solution was evidenced by a significant increase of about $60 \%$ in ASI (10.62 \pm 1.32 vs $6.64 \pm 1.29$ for the control group; Figure 4). On the other hand, a tendency to an increased ASI was observed in Ang IIperfused hearts $(8.00 \pm 1.84$ vs $6.64 \pm 1.29$ for the control group, $\mathrm{P}>0.05$; Figure 4). In addition, there was an increase in the occurrence of irreversible arrhythmias ranging from $27 \%$ in control hearts to $75 \%$ and $50 \%$ in the hearts perfused with Krebs-Ringer solution containing Ang-(1-7) and Ang II, respectively (Figure 4). Perfusion of isolated hearts with Krebs-Ringer containing low $\mathrm{Ca}^{2+}$ reduced the ASI from a value of $6.64 \pm 1.29$ observed in normal Krebs-Ringer solution to $1.40 \pm 0.40$, and abolished the occurrence of irreversible arrhythmias. In addition, low-Ca ${ }^{2+}$ Krebs-Ringer prevented the arrhythmogenic effect of Ang-(1-7) and Ang II (Figure 4).

\section{Discussion}

In the present study we observed that Ang-(1-7) produced a concentration-dependent reduction in coronary flow in isolated rat hearts. More important, Ang-(1-7) enhanced
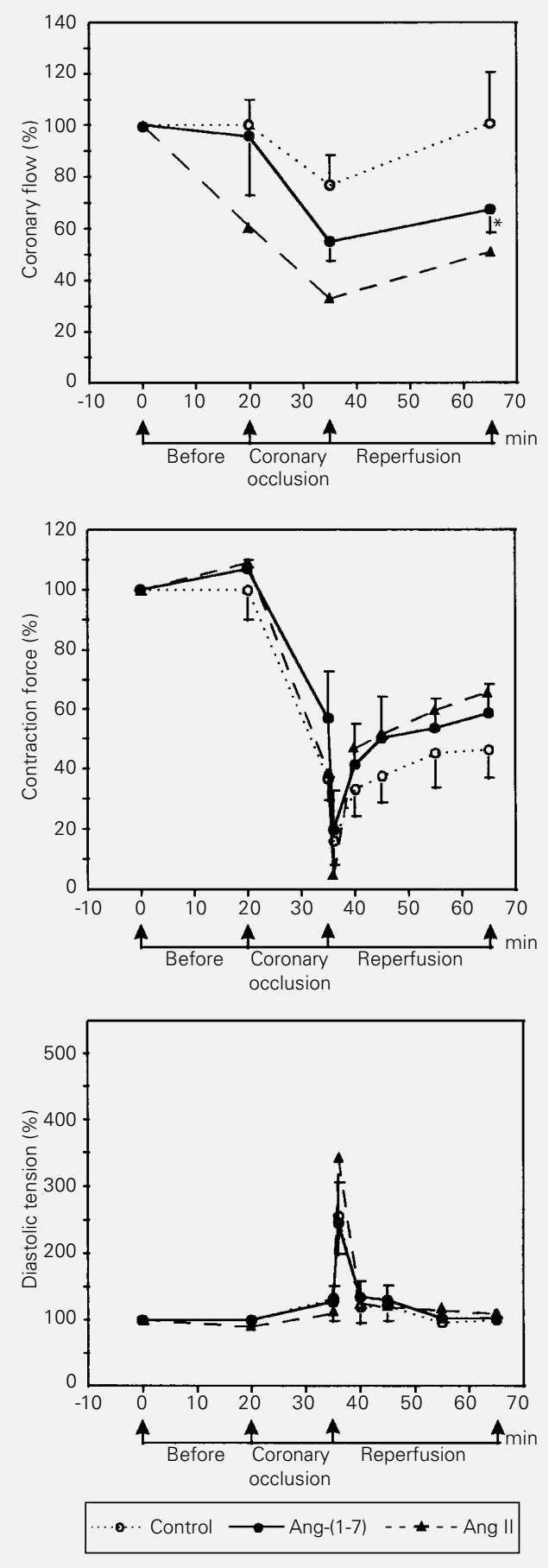

Figure 3 - Coronary flow (upper), contraction force (middle) and diastolic tension (lower) in isolated rat hearts perfused with low-Ca ${ }^{2+}$ Krebs-Ringer solution (control, $\mathrm{N}=5$ ), low-Ca ${ }^{2+}$ KrebsRinger solution containing 27 nM Ang-(1-7) ( $\mathrm{N}=4)$ or low-Ca2+ Krebs-Ringer solution containing $27 \mathrm{nM}$ Ang II (N = 2) before and after (reperfusion) coronary occlusion. Percentage was calculated in relation to the last value at the equilibration period. ${ }^{*} P<0.05$ compared to the control group (ANOVA followed by the Least Significant Difference test). 
Figure 4 - Averaged arrhythmia severity index (upper panel) and percentage of irreversible arrhythmias (more than $30 \mathrm{~min}$ ) (lower panel) upon reperfusion after 15 min of occlusion of the left anterior descending coronary artery in isolated rat hearts perfused with normal or low$\mathrm{Ca}^{2+}$ Krebs-Ringer solution (control), normal or low-Ca ${ }^{2+}$ KrebsRinger solution containing 27 nM Ang-(1-7) or normal or low$\mathrm{Ca}^{2+}$ Krebs-Ringer solution containing $27 \mathrm{nM}$ Ang II. Numbers above the bars indicate the incidence of irreversible arrhythmias during the reperfusion period. ${ }^{*} \mathrm{P}<0.05$ in comparison to the control group (Student $t$-test). ${ }^{*} \mathrm{P}<0.01$ compared to the respective group submitted to normal Krebs-Ringer solution (Student $t$-test)
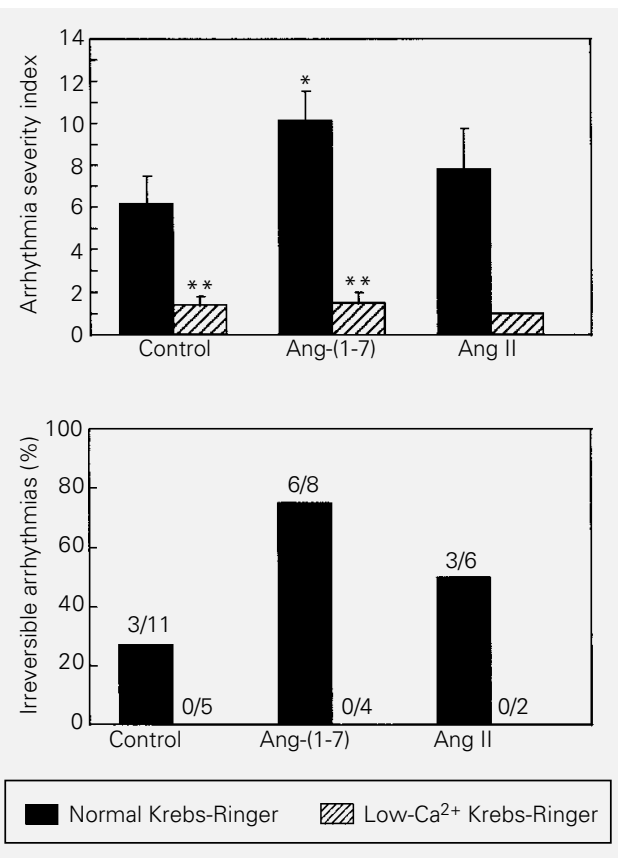

reperfusion arrhythmias. The increase in diastolic tension and the decrease in contraction force observed during the post-ischemic period in isolated rat hearts were also potentiated by Ang-(1-7). These effects resembled those produced by Ang II. However, these two peptides differed significantly in their action on basal force and frequency. Ang II produced a significant increase in force and a decrease in frequency while Ang-(1-7) produced only slight and inconsistent changes in these parameters.

Our data confirm and extend previous observations showing that the heptapeptide Ang-(1-7) is a biologically active end-product of the renin-angiotensin system $(4,5,18$, 19). The selectivity of the biological action of Ang-(1-7) reported previously $(4,18,20)$ is apparently also true for isolated rat hearts. Although Ang-(1-7) and Ang II decreased coronary flow, Ang-(1-7) did not significantly change the contraction force or heart rate, which were significantly modified by Ang II. In addition, Ang-(1-7) was more potent in inducing arrhythmogenesis under our experimental conditions. As pointed out earlier, the selectivity of Ang-(1-7) is prob- ably related to the absence of phenylalanine at the carboxyl terminus (4).

A vasoconstrictor effect of Ang-(1-7) on the coronary vessels was first reported by Kumagai et al. (21) in isolated hamster hearts. However, it has been recently reported that Ang-(1-7) has a vasodilator effect on canine coronary arteries (13). These contrasting observations may be related to species differences. In this regard, the vasodilator effect of Ang-(1-7) on the feline hindquarter vascular bed is mainly dependent on the release of nitric oxide (22), while in pithed rats Ang-(1-7) produced systemic vasodilatation dependent on prostaglandin release (23). Although the mechanism of the vasoconstrictor effect of Ang-(1-7) in the isolated rat heart was not investigated a likely explanation is that it depends, at least in part, on the release of coronary vasoconstrictors (14).

The arrhythmogenic effect of Ang II has been attributed to its vasoconstrictor action and to its facilitatory effect on sympathetic neurotransmission (3). Alternatively, Ang II may promote reperfusion arrhythmias by stimulating phospholipase $\mathrm{C}$ and/or $\mathrm{A}_{2}$, thus enhancing the formation of free radicals via the arachidonic acid pathway (24). Our observation that the arrhythmogenic effect of Ang II was absent in the two isolated hearts perfused with low-Ca ${ }^{2+}$ Krebs-Ringer also suggests an important role for $\mathrm{Ca}^{2+}$ in this mechanism. However, these data should be interpreted with caution due to the small number of isolated hearts used. Although we have no data regarding the mechanism of the Ang-(1-7) arrhythmogenic effect, it appears that $\mathrm{Ca}^{2+}$ also plays an important role. This finding contrasts with a previous study on CRTG3 cells showing that Ang-(1-7) induced the release of prostaglandins independent of $\mathrm{Ca}^{2+}$ mobilization (25). It should be pointed out, however, that Fura 2, the compound used to study $\mathrm{Ca}^{2+}$ transport in the study by Tallant et al. (25), could inhibit some types of calcium mobilization such as 
that induced by ATP, through $\mathrm{IP}_{3}$ receptors in megakaryocytes (26). Activation of phospholipase $\mathrm{A}_{2}$, as demonstrated in rat proximal tubular cells (27), and facilitation of sympathetic neurotransmission (14) are also likely mechanisms involved in the Ang-(17) arrhythmogenic effects in isolated rat hearts.

We have found that in isolated hearts perfused with normal Krebs-Ringer solution Ang-(1-7) facilitated the decrease in force observed during the post-ischemic period. The absence of this effect in isolated hearts perfused with a low-Ca ${ }^{2+}$ Krebs-Ringer solution suggests that Ang-(1-7) could be acting by facilitating the increase in cytosolic $\mathrm{Ca}^{2+}$ usually observed during the reperfusion period (28). This increased cytosolic $\mathrm{Ca}^{2+}$ may impair myocardial function by several mechanisms including impairment of mitochondrial function and activation of $\mathrm{Ca}^{2+}$-ATPases leading to a reduction in intracellular ATP, or by activation of $\mathrm{Ca}^{2+}$ lipases (28).

We have observed that Ang II produced a dose-dependent positive inotropic effect in Krebs-Ringer-perfused hearts. This finding is in contrast to previous studies showing that Ang II has no inotropic effect on the heart of adult rats (29). Ang II, however, has been reported to stimulate contractility in isolated adult rat ventricular myocytes (30). In addition, Ang II has been reported to produce a direct positive chronotropic effect in cultured neonatal rat heart cells (31). However, we found a negative chronotropic effect, not dose dependent, in rat hearts perfused with normal Krebs-Ringer solution. No chronotropic effect was observed in hearts perfused with low-Ca ${ }^{2+}$ Krebs-Ringer solution.

Similarly to Ang II, Ang-(1-7) produced a reduction in coronary blood flow and facilitated reperfusion arrhythmias whereas its effect on cardiac force under basal conditions was not consistent, in contrast to the significant increase in force produced by
Ang II. This selectivity indicates that different angiotensin receptor subtypes are involved in the mediation of the Ang-(1-7) and Ang II effects. All the known actions of Ang II in the heart appear to be mediated mainly by the $\mathrm{AT}_{1}$ receptor subtype $(32,33)$. The receptor(s) mediating the Ang-(1-7) effects remains to be determined. Although no direct data were obtained in this study, recent reports strongly indicate that a selective Ang(1-7) receptor may exist $(4,13)$. We have recently found that central and peripheral actions of Ang-(1-7) can be blocked by its analog, compound A-779, which does not change the pressor, myotropic or dipsogenic effects of Ang II (20). On the other hand, the cardiovascular effects produced by microinjection of Ang-(1-7) into the rostral ventrolateral medulla (4) or its vasodilator effect on canine coronary arteries (13) could not be blocked by $\mathrm{AT}_{1}$ or $\mathrm{AT}_{2}$ angiotensin receptor antagonists. In contrast, Gironacci et al. (14) have recently reported that the facilitatory effect of Ang-(1-7) on the release of $\left[{ }^{3} \mathrm{H}\right]$ norepinephrine in isolated rat atria could be blocked by either DUP 753 or the $\mathrm{AT}_{2}$ antagonist PD 123177. This observation suggests that the Ang-(1-7) receptor in the rat heart resembles the $\mathrm{AT}_{1}$ receptor subtype described by Ernsberger et al. (34) in rat mesangial cells.

The pharmacological effects of ACE inhibitors have been attributed to a reduction in Ang II generation or to an increase in bradykinin levels (3). We have previously shown that Ang-(1-7) can be formed by an ACE-independent pathway (7-9). In accordance with this finding, a marked increase in Ang-(1-7) has been observed in rats or patients chronically treated with ACE inhibitors $(11,12)$. These data illustrate the importance of determining the effects of Ang-(1-7) which could be involved in the mechanism of action of ACE inhibitors. In this regard, the present study indicates that the heart is an important site for the actions of this endogenous biologically active angiotensin. Further 
studies are necessary to elucidate whether the results obtained in our study for isolated rat hearts are also demonstrable in vivo and/ or in other species.

\section{Acknowledgments}

\author{
We wish to thank Paulo Cesar Nogueira \\ and Kátia Marques for technical assistance.
}

\section{References}

1. Dzau VJ (1988). Cardiac renin-angiotensin system: molecular and functional aspects. American Journal of Medicine, 84: 22-27.

2. Lindpaintner K \& Ganten D (1991). The cardiac renin-angiotensin system: an appraisal of present experimental and clinical evidence. Circulation Research, 68: 905-921.

3. Grinstead WC \& Young JB (1992). The myocardial renin-angiotensin system: existence, importance, and clinical implications. American Heart Journal, 123: 1039-1045.

4. Santos RAS \& Campagnole-Santos MJ (1994). Central and peripheral actions of angiotensin-(1-7). Brazilian Journal of Medical and Biological Research, 27: 1033-1047.

5. Schiavone MT, Santos RAS, Brosnihan KB, Khosla MC \& Ferrario CM (1988). Release of vasopressin from the hypothalamo-neurohypophyseal system by angiotensin-(1-7) heptapeptide. Proceedings of the National Academy of Sciences, USA, 85: 4095-4098.

6. Sardinia MF, Hanesworth JM, Krebs LT \& Harding JW (1993). AT4 receptor binding characteristics: D-amino acid- and glycinesubstituted peptides. Peptides, 14 : 949-954.

7. Santos RAS, Brosnihan KB, Chappell MC, Pesquero JL, Chernicky CL, Greene LJ \& Ferrario CM (1988). Converting enzyme activity and angiotensin metabolism in the dog brainstem. Hypertension, 11: I.230I.238.

8. Santos RAS, Brum JM, Brosnihan KB \& Ferrario CM (1990). The renin-angiotensin system during acute myocardial ischemia in dogs. Hypertension, 15: I.121-I.127.

9. Santos RAS, Brosnihan KB, Jacobsen DW, DiCorleto PE \& Ferrario CM (1992). Production of angiotensin-(1-7) by human vascular endothelium. Hypertension, 19: II.56-II.61

10. Timmermans PBMWM, Wong PC, Chiu AT, Herblin WF, Benfield P, Carini DJ, Lee RJ, Wexler RR, Saye JAM \& Smith RD (1993). Angiotensin II receptors and angiotensin II receptor antagonists. Pharmacological Reviews, 45: 205-251.
11. Campbell DJ, Lawrence AC, Towrie A, Kladis A \& Valentijn AJ (1991). Differential regulation of angiotensin peptide levels in plasma and kidney of the rat. Hypertension, 18: 763-773.

12. Lawrence AC, Evin G, Kladis A \& Campbell DJ (1990). An alternative strategy for the radioimmunoassay of angiotensin peptides using amino-terminal-directed antisera: measurement of eight angiotensin peptides in human plasma. Journal of Hypertension, 8: 715-724.

13. Brosnihan KB, Li P \& Ferrario CM (1996). Angiotensin-(1-7) dilates canine coronary arteries through kinins and nitric oxide. Hypertension, 27: 523-528.

14. Gironacci MM, Adler-Graschinsky E, Peña C \& Enero MA (1994). Effects of angiotensin II and angiotensin-(1-7) on the release of $[3 \mathrm{H}]$ norepinephrine from rat atria. Hypertension, 24: 457-460.

15. Lubbe WF, Daries PS \& Opie LH (1978) Ventricular arrhythmias associated with coronary artery occlusion and reperfusion in the isolated perfused rat heart: a model for assessment of antifibrillatory action of antiarrhythmic agents. Cardiovascular Research, 12: 212-220.

16. Bernauer W (1986). The effect of ethanol on arrhythmias and myocardial necrosis in rats with coronary occlusion and reperfusion. European Journal of Pharmacology, 126: 179-187.

17. Bernauer W \& Ernenputsch I (1988). Antagonistic effects of $\alpha$-adrenoceptor blocking agents on arrhythmias, enzyme released and myocardial necrosis in isolated rat hearts with coronary occlusion and reperfusion. Naunyn-Schmiedeberg's Archives of Pharmacology, 338: 88-95.

18. Campagnole-Santos MJ, Heringer SB, Batista EN, Khosla MC \& Santos RAS (1992). Differential baroreceptor reflex modulation by centrally infused angiotensin peptides. American Journal of Physiology, 263: R89-R94.

19. Ferrario $\mathrm{CM}$, Barnes $\mathrm{KL}$, Block $\mathrm{CH}$, Brosnihan KB, Diz DI, Khosla MC \& Santos RAS (1990). Pathways of angiotensin formation and function in the brain. Hypertension, 15: I.13-I.19.
20. Santos RAS, Campagnole-Santos MJ Baracho NCV, Fontes MAP, Silva LCS, Neves LAA, Oliveira DR, Caligiorne SM, Rodrigues ARV, Gropen Jr C, Carvalho WS, Simoes e Silva AC \& Khosla MC (1994). Characterization of a new angiotensin antagonist selective for angiotensin-(1-7): Evidence that the actions of angiotensin-(1-7) are mediated by specific angiotensin receptors. Brain Research Bulletin, 35: 293-298.

21. Kumagai $H$, Khosla MC, Ferrario C \& Fouad-Tarazi FM (1990). Biological activity of angiotensin-(1-7) heptapeptide in the hamster heart. Hypertension, 15: I.29-I.33.

22. Osei SY, Ahima RS, Minkes RK, Weaver JP, Khosla MC \& Kadowitz PJ (1993). Differential responses to angiotensin-(1-7) in the feline mesenteric and hindquarters vascular beds. European Journal of Pharmacology, 234: 35-42.

23. Benter IF, Diz DI \& Ferrario CM (1993) Cardiovascular actions of angiotensin-(17). Peptides, 14: 679-684.

24. Linz W, Scholkens BA \& Han YF (1986) Beneficial effects of the converting enzyme inhibitor, ramipril, in ischemic rat hearts. Journal of Cardiovascular Pharmacology, 8: S91-S99.

25. Tallant EA, Jaiswal N, Diz DI \& Ferrario CM (1991). Human astrocytes contain two distinct angiotensin receptor subtypes. Hypertension, 18: 32-39.

26. Akaike N \& Uneyama H (1994). ATP-induced $\mathrm{K}^{+}$current oscillation in megakaryocytes: a unique purinoceptor. News in Physiological Sciences, 9: 49-53.

27. Andreatta-Van Leyen S, Romero MF Khosla MC \& Douglas JG (1993). Modulation of phospholipase $\mathrm{A}_{2}$ activity and sodium transport by angiotensin-(1-7). Kidney International, 44: 932-936.

28. Nayler WG (1981). The role of calcium in the ischemic myocardium. American Journal of Physiology, 102: 262-270.

29. Doggrell SA (1989). The effects of atriopeptin and angiotensin on the rat right ventricle. Genetic Pharmacology, 20: 253257. 
30. Neyses L \& Vetter H (1989). Action of atrial natriuretic peptide and angiotensin II on the myocardium: studies in isolated rat ventricular cardiomyocytes. Biochemical and Biophysical Research Communications, 163: 1435-1443.

31. Allen IS, Cohen NM, Dhallan RS, Gaa ST, Lederer WJ \& Rogers TB (1988). Angiotensin II increases spontaneous contractile frequency and stimulates calcium current in cultured neonatal rat heart myocytes: Insight into the underlying biochemical mechanisms. Circulation Research, 62: 524-534.
32. Feolde E, Vigne P \& Frelin C (1993). Angiotensin II receptor subtypes and biological responses in the rat heart. Journal of Molecular and Cellular Cardiology, 25: 1359-1367.

33. Wiemer G, Scholkens BA, Wagner A, Heitsch H \& Linz W (1993). The possible role of angiotensin II subtype AT2 receptors in endothelial cells and isolated ischemic rat hearts. Journal of Hypertension, 11: S234-S235.
34. Ernsberger P, Zhou J, Damon TH \& Douglas JG (1992). Angiotensin II receptor subtypes in cultured rat renal mesangial cells. American Journal of Physiology, 263: F411-F416. 